\title{
Article
}

\section{Bio-resorption control and biological response of Magnesium alloy AZ31 coated with poly- $\beta$-hydroxybutyrate}

\author{
Lu Wang ${ }^{1,2}$, Zhengjun Houa ${ }^{1}$, Jie Tian', Shuang Liang1, Shuping Ge ${ }^{1,3}$, Yu Chen ${ }^{2}$, Raffaella Aversa ${ }^{4}$, \\ Valeria Perrotta ${ }^{4}$, Antonio Apicella ${ }^{4,}$, , Davide Apicella ${ }^{4}$, GuixueWang ${ }^{1, *}$
}

1 Key Laboratory for Biorheological Science and Technology of Ministry of Education, State Key Laboratory of Mechanical Transmission, State and Local Joint Engineering Laboratory for Vascular Implants, Bioengineering College of Chongqing University, Chongqing, 400044, China; wanggx@cqu.edu.cn (GW)

2 School of Biological Information, Chongqing University of Posts and Telecommunications, Chongqing, 400065, China; 1946271974@qq.com

3 School of Chemistry and Chemical Engineering, Chongqing University of Technology, Chongqing, China;

4 Advanced Materials Lab, Dept. of Architecture and Industrial Design University of Campania, via San Lorenzo, 81031 Aversa, Italy; antonio.apicella@unicampania.it (AA); raffaella.aversa@unicampania.it (RA); valeria.perrotta@unicampania.it (VP); dott.davide.apicella@outlook.it (DA)

* Correspondence: antonio.apicella@unicampania.it (AA); wanggx@cqu.edu.cn (GW)

Featured Application: Tunable bio-active and bio-resorbable metal implants

\begin{abstract}
Magnesium and its alloys are not normally used as bio-resorbable temporary implants due to their high and uncontrolled degradation rate in physiological liquid environment. The improvement of corrosion resistance to simulated body fluids (SBF) of a Magnesium alloy (AZ31) coated with poly- $\beta$-hydroxybutyrate (PHB) was investigated. Scanning electron microscopy, Fourier transform infrared spectrometer, and contact angle measurements were used to characterize surface morphology, material composition and wettability, respectively. $\mathrm{pH}$ modification of the SBF corroding medium, mass of $\mathrm{Mg}^{2+}$ ions released, and weight loss of the samples exposed to the SBF solution, and electrochemical experiment were used to describe the corrosion process and its kinetics. Materials biocompatibility was described by evaluating the effect of corrosion by products collected in the SBF equilibrating solution on hemolysis ratio, cytotoxicity, Nitric Oxide (NO), and total antioxidant capacity (T-AOC). The results showed that the PHB coating can diffusively control the degradation rate of Magnesium alloy improving its biocompatibility: hemolysis rate of materials was lower than 5\%, while in vitro Human Umbilical Vein Endothelial Cells (HUVECs) compatibility experiments showed that PHB coated $\mathrm{Mg}$ alloy promoted cell proliferation and had no effect on the NO content, the T-AOC was enhanced compared with the normal group and bare AZ31 alloy. PHB coated AZ31 Magnesium alloy extraction fluids have a less toxic behavior due to the lower concentration of corrosion by-products deriving from the diffusion control exerted by the PHB coating films both from metal surface to the solution and vice versa. These findings provide more reference value for the selection of such system as tunable bioresorbable prosthetic materials
\end{abstract}

Keywords: Bioresorbable implants, Magnesium alloy, PHB, Biocompatibility, Cytotoxicity, NO, temporary implants

\section{Introduction}

Biological implants have been widely used in various applications nowadays and most of these biomedical devices are made in different biomaterials designed to stay permanently in the body. However, often, due to complications such as long-term endothelial dysfunction, delayed reendothelialization, late thrombosis, permanent physical irritation, toxic metal ion release, and local chronic inflammation such long-term implantations may often need secondary surgeries to remove them [1-4]. 
Several bioresorbable materials have been then proposed to overcome these longterm limitations associated with permanent implant materials and, among these, Magnesium is still attracting significant attention for its light weight, good mechanical properties and compatibility with human physiology [5].

Another intriguing characteristic of Magnesium is its osteoconductive activity that has been described to occur in clinical trials as an increase of bone apposition in magnesium-based implants [6] and, since early studies [7,8], it has been assessed that the presence of $\mathrm{Mg}$ structures for human bone fractures reduction decrease the time for hard callous formation. The presence of $\mathrm{Mg}$ ions is a crucial co-factor for many enzymatic metabolic activities [6,7] that facilitates tissue-healing [8]. Moreover, even when in excess, $\mathrm{Mg}$ ions do not often cause cellular toxicity since they are readily expelled with body excretions [9].

Unfortunately, pure Magnesium is not directly suitable for such applications due to its insufficient mechanical and corrosion properties. Magnesium alloys have been than considered since overcoming most of these difficulties [8,10-16]. However, not all of them could be considered as proper materials for the resorbable medical implants especially when containing high concentration of elements such as Zirconium, Aluminum, and rare earths metals that may induce inflammatory cascades and tissue damage [5,15-20]. The Magnesium alloy AZ31, which is characterized by a relatively low content of Aluminum $(3 \%)$ and Zinc $(1 \%)$, has been experimentally proved to possess good biocompatibility $[11,12]$.

Due to its good balance between mechanical, biocompatibility and biodegradation characteristics may be a suitable bioresorbable implants material. However, it should be considered that since several clinical treatments, such as bone healing, may require up to 12 weeks to be completed [5], material with more reliable and controlled corrosion kinetics should be adopted to avoid that bio-resorption occurs before tissues healing was accomplished. Uncontrolled or high corrosion rates in the physiological environment may result in the bioresorbable implant early embrittlement and loss of structural integrity [14]. Technological solutions that enable reduction and control of the degradation rates can favor a wider utilization of biodegradable temporary implants avoiding concerns about metal fix implants [22].

Different approaches, such as alloy composition, surface modification, and conversion coatings, have been proposed to improve and to better control the corrosion kinetics of Magnesium alloys [14, 22-26]. Namely, ion implantation [27-29], organic coatings [3033], alkali heat treatment, micro-arc oxidation [34-36], and polymer coating [37-39] have been proposed. Among these, biodegradable polymer coatings have been described to have better performance [40-42], even if not yet providing proper coating durability and good biocompatibility.

PHB (Poly- $\beta$-hydroxybutyrate) is a natural macromolecule polymer secreted by microorganisms under the condition of unbalanced growth that has been chosen for our study as biodegradable protecting and corrosion rate controlling coating for Magnesium alloy [32].

PHB and its copolymers are already used in a wide range of applications for drug release and tissue engineering since it is naturally and not toxically biodegraded in $\mathrm{CO}_{2}$ and $\mathrm{H}_{2} \mathrm{O}$ by the human metabolism do not causing body immune exclusion. Tissue response to PHB degradation by-products is debated. Although reported rat subcutaneous tissue reactions following implantation of PHB and PHB/VA [43], hypothesizing that mononuclear giant cells infiltrate hyperplasia of fibroblasts and mature fibrous capsule were a typical reaction associated with an increase in the collagen deposition induced by PHB degradation by-products, in vivo tests run [44] using PHB films implanted subcutaneously in rabbits legs for 8 weeks, showed the presence of macrophages do not accompanied by any acute inflammation or abscess formation. The experiment suggested that PHB material has good biocompatibility and biodegradation [45] associated to good chemical and mechanical properties for biomedical applications [45-47]. 
In the present work, both surface characterization and biological response of Magnesium alloy AZ31 coated with Poly-b-hydroxybutyrate (PHB) will be then evaluated to investigate whether it can induce low hemolysis and its effects on cell viability. Such experimental research will provide a preliminary evaluation of Magnesium alloys with PHB coating as vascular stents and hard tissue repair materials and it will serve as base and reference for their future potential clinical applications.

\section{Materials and Methods}

\subsection{Materials:}

Magnesium AZ31 alloy extruded bars with chemical composition (wt.\%) 2.89 Al, 0.92 $\mathrm{Zn}, 0.05 \mathrm{Mn}, 0.01 \mathrm{Si}, 0.002 \mathrm{Cu}, 0.001 \mathrm{Ni}, 0.004 \mathrm{Fe}$ and the complement 96.123 of $\mathrm{Mg}$ were obtained from Guangdong Dongguan Hongxing Metal Materials co., LTD, China. Reagent grade poly(b-hydroxybutyrate) (PHB) was purchased from Santa Cruz Biotechnology, CA, USA.

\subsection{Preparation of $\mathrm{Mg}$ alloy disks and coating procedures:}

Specimens were cut from the AZ31 Magnesium alloy bars. Small disks with dimensions $13 \mathrm{~mm}$ diameter and $2 \mathrm{~mm}$ thickness were obtained. Each sample was mechanically ground up with 1200-grit SiC paper, ultrasonically cleaned in acetone, and rinsed with ethanol and distilled water. PHB was dissolved in trichloromethane (analytical grade) at a concentration of $1 \mathrm{wt} \%$. Organic PHB dip coating on Mg AZ31 alloy disk was carried out by a two-step process: first a $2 \mathrm{hrs}$ hydrothermal treatment at $100^{\circ} \mathrm{C}$ [43], which scope was to obtain an uniform surface for all samples with a homogeneous $\mathrm{Mg}(\mathrm{OH})_{2}$ layer that favors polymer coating adhesion, was carried out followed by dip coating in the PHB solution with subsequent solvent evaporation at $20^{\circ} \mathrm{C}$ for $24 \mathrm{~h}$. Magnesium AZ31 alloy control specimens without polymer coating were also collected after the hydrothermal treatment. Polymer coating thickness was indirectly determined by gravimetric measurements of the samples before and after the coating procedure. Sample weight increase after solvent evaporation of the $1 \%$ polymer solution was rationally assumed to be due to the formation of a homogeneous thin polymer film covering the entire sample surface which thickness has been extrapolated considering the exposed surface area of the sample (3.47 $\left.\mathrm{cm}^{2}\right)$ and PHB polymer density $\left(1.25 \mathrm{~g} / \mathrm{cm}^{3}\right)$. The gravimetric calculated mean coating thickness was $52 \pm 6 \mu \mathrm{m}$.

\subsection{Alloy surface morphological and chemio-physical characterization:}

The surface morphology of the specimens was analyzed by scanning electron microscopy (SEM) (Vega III-LMH, Tescan, Czech Republic). Molecular structure and chemical composition of the surface material were investigated by Fourier transform spectrum (FTIR). Sample wettability was determined by using a contact angle meter (Future Digital Scientific, Taiwan).

\subsection{Electrochemical analysis:}

Electrochemical measurements were performed by utilizing an electro-chemical workstation (Chen Hua CH604B, Shanghai) with a three-electrode setup: the specimen as working electrode $\left(1 \mathrm{~cm}^{2}\right.$ area exposed), a platinum sheet as counter-electrode and a saturated calomel electrode (SCE) as reference electrode. $50 \mathrm{ml}$ deoxygenated $\mathrm{m}-\mathrm{SBF}$ incubated in a water bath at $37 \pm 0.2{ }^{\circ} \mathrm{C}$ served as electrolyte. Potentio-dynamic polarization curves were scanned from $-2 \mathrm{~V}$ to $-1 \mathrm{~V}$ at a scan rate of $2 \mathrm{mV} / \mathrm{s}$. The natural corrosion current ( $\left.\mathrm{I}_{\text {corr }}\right)$ and natural corrosion potential ( $\left.\mathrm{E}_{\mathrm{corr}}\right)$ were determined by Tafel extrapolation.

\subsection{Static degradation tests:}

The corrosion tests on reference and PHB coated Magnesium AZ31 alloy were carried out at $37{ }^{\circ} \mathrm{C}$ in a simulated body fluid (SBF), which composition in mmol/l is reported in 
Table 1, following metal corrosion test standard ASTM-G31-72. Namely, solution volumeto-sample area ratio should be between $20 \mathrm{ml} / \mathrm{cm} 2$ and $40 \mathrm{ml} / \mathrm{cm} 2$, in our test the selected ratio was $30 \mathrm{ml} / \mathrm{cm} 2$. Identical reference and coated samples were immersed in separate flasks containing the same corrosion fluid (SBF). We daily collected SBF solution samples to measure their $\mathrm{pH}$ values (by electrochemical $\mathrm{pH}$ meter), the Magnesium ions concentration (by Inductively Coupled Plasma-Mass Spectrometer) and as culture medium to run the biological tests. After daily sampling, SBF solutions were renewed for all samples over the entire period of the corrosion tests (15 days). Uncoated and coated samples individual measurements had four repetitions. At one day time intervals, a group of PHB coated and uncoated AZ31 disks was daily removed from the SBF, gently rinsed, and cleaned with 180-200 g/L Chromium trioxide for 5-10 minutes and then air dried for individual gravimetrically measure of their daily weight losses as a function of SBF exposure time.

According to gravimetric and Inductively Coupled Plasma-Mass Spectrometry, corrosion rates were respectively evaluated as daily weight loss $\left(\mathrm{mg} / \mathrm{cm}^{2}\right.$ per day) and daily released $\mathrm{Mg}^{2+}$ ions mass (mg/ $\mathrm{cm}^{2}$ per day). Moreover, following the ASTM-G31-72, corrosion rate has been also evaluated as $\mu \mathrm{m}$ /day both from gravimetric and mass spectrometry measurements.

Table 1. The concentration of inorganic ions in Simulating Body Fluid (SBF) and blood plasma.

\begin{tabular}{ccc}
\hline Ions & Plasma, $\mathbf{~ m m o l} / \mathbf{l}$ & SBF, $\mathbf{~ m m o} / \mathbf{l}$ \\
\hline $\mathrm{Na}^{+}$ & 142.0 & 142.0 \\
$\mathrm{~K}^{+}$ & 5.0 & 5.0 \\
$\mathrm{Mg}^{2+}$ & 1.5 & 1.5 \\
$\mathrm{Ca}^{2+}$ & 2.5 & 2.5 \\
$\mathrm{Cl}^{-}$ & 103.0 & 147.8 \\
$\left(\mathrm{HCO}_{3}\right)^{-}$ & 27.0 & 4.2 \\
$\left(\mathrm{HPO}_{4}\right)^{2-}$ & 1.0 & 1.0 \\
$\left(\mathrm{SO}_{4}\right)^{2-}$ & 0.5 & 0.5 \\
$\mathrm{pH}^{-}$ & $7.2-7.4$ & 7.4 \\
\hline
\end{tabular}

\subsection{Cell culture:}

HUVECs were cultured in endothelial basal media (RPMI 1640; HyClone, USA) and Dulbecco's Modified Eagle Medium/F12 (DMEM/F12), respectively, both were supplemented with 10\% fetal bovine serum (FBS; Cambrex Corp, USA) and 1\% antibiotic/antimycotics solution (Gibco Industries Inc, USA). Cells were grown to confluence in T-75 culture flasks (Falcon, BD Biosciences, USA) at $37{ }^{\circ} \mathrm{C}$ under $5 \% \mathrm{CO}_{2}$.

\subsection{Cytotoxicity assessments:}

The effect of metal ions released from magnesium alloys was evaluated by using Cell Counting Kit-8(CCK-8) (Beyotime Biotechnology, China) to determine the percentage of viable human umbilical vein endothelial cells (HUVECs) in extract solutions exposed to different concentrations. The cells were cultured in RPMI1640 media (Hyclone, USA), 10\% fetal bovine serum, FBS (Gibco, USA), and Penicillin-Streptomycin at $37^{\circ} \mathrm{C}$ in a humidified atmosphere with 5\% CO 2 . The AZ31 alloys were immersed in RPMI1640 media for 72 $\mathrm{h}$ (the ratio of the sample surface area and extraction medium using $1.25 \mathrm{~cm}^{2} / \mathrm{ml}$ ). The leaching solution was prepared at concentrations of $25 \%, 50 \%$ and $100 \%$, respectively. Cells were counted $\left(2 \times 10^{4}\right.$ cells) using hemocytometer and plated in 96-well plates with $200 \mu \mathrm{l}$ of culture media per well. The cells were incubated for $24 \mathrm{~h}$ to allow attachment. After the 24-hours incubation, the culture media was replaced with culture media exposed to magnesium alloys. Pure culture media with cells was used as control. The cells were incubated for $24 \mathrm{~h}$. After the $24 \mathrm{~h}, 100 \mu \mathrm{l}$ of media were removed from the 96-well plates, the remaining $100 \mu \mathrm{l}$ media was treated with $20 \mu \mathrm{l} /$ well with CCK Solution Reagent. The 96-well plates were placed in the incubator for $4 \mathrm{~h}$. After the incubation period, the optical 
density measurements were recorded using ELx800 ${ }^{\mathrm{TM}}$ BioTek absorbance microplate reader controlled byGen 5 software with a $490 \mathrm{~nm}$ absorbance excitation filter.

\subsection{Hemolysis assessments:}

Healthy human blood from a volunteer containing sodium citrate (3.8 wt.\%) in the ratio of 9:1 was taken and diluted with normal saline (4:5 ratio by volume). Samples were dipped in a $15 \mathrm{~mL}$ centrifuge tube containing $10 \mathrm{~mL}$ of normal saline which had been previously incubated at $37^{\circ} \mathrm{C}$ for $30 \mathrm{~min}$. Then $0.2 \mathrm{~mL}$ of diluted blood was added to this standard tube and the mixtures were incubated for $60 \mathrm{~min}$ at $37^{\circ} \mathrm{C}$. Similarly, normal saline solution was used as a blank control and deionized water as a positive control. After that, all the tubes were centrifuged for $5 \mathrm{~min}$ at $3000 \mathrm{rpm}$ and the supernatant was carefully removed and transferred to the 96-well plates for spectroscopic analysis at $545 \mathrm{~nm}$.

The hemolysis, based on the average of three replicates, was evaluated by optical density (OD) measurements using an ultraviolet spectrophotometer (UNIC-7200, China) according to Eq. (1):

$$
\text { Hemolysis }=\left(O D_{\text {test }}-O D_{\text {negative control }}\right) /\left(O D_{\text {positive control }}-O D_{\text {negative control }}\right) \times 100 \% \text {, }
$$

$O D_{\text {test }}$ stands for the optical density of test group, $O D_{\text {negative control stands for that of normal }}$ saline control group, and $O D_{\text {positive control }}$ stands for that of deionized water group.

\subsection{Nitric Oxide (NO) assessments:}

Cells were counted $\left(2 \times 10^{4}\right.$ cells) using hemocytometer and plated in 24 -well plates with $500 \mu \mathrm{l}$ of cell suspension per well. Pure culture media with cells was used as control. After $24 \mathrm{~h}$, SBF corrosion extraction fluids at different dilutions were used to replace the original culture medium, and the supernatant was obtained after 24 hours of culture. Experimental procedures were performed in accordance with Nitric Oxide (NO) assay kit (Nanjing Jiancheng Bioengineering Institute, China). The absorbance of each well was measured at the $570 \mathrm{~nm}$ of the microplate reader.

\subsection{Total Antioxidant Capacity (T-AOC) assessments:}

Cells were counted $\left(2 \times 10^{4}\right.$ cells $)$ using hemocytometer and plated in 24 -well plates with $1 \mathrm{~mL}$ of cell suspension per well. The following experimental procedures were performed in accordance with Total Anti-Oxidant Capacity (T-AOC) assay kit (Nanjing Jiancheng Bioengineering Institute, China).

\subsection{Statistical analysis:}

Each experiment was repeated at least three times, and the data are expressed as the mean \pm the standard deviation (SD). Comparisons among values for all groups were performed by one-way analysis of variance (ANOVA). Holm's t-test was used for analysis of differences between different groups. Differences were significant at $\mathrm{P}<0.05$.

\section{Results}

\subsection{Morphological and electrochemical characterization of the samples surfaces}

Scanning Electron micrographs (7500x) of the surface morphologies of the uncoated and PHB-coated AZ31 samples are shown in Figure 1a and Figure 1b. 

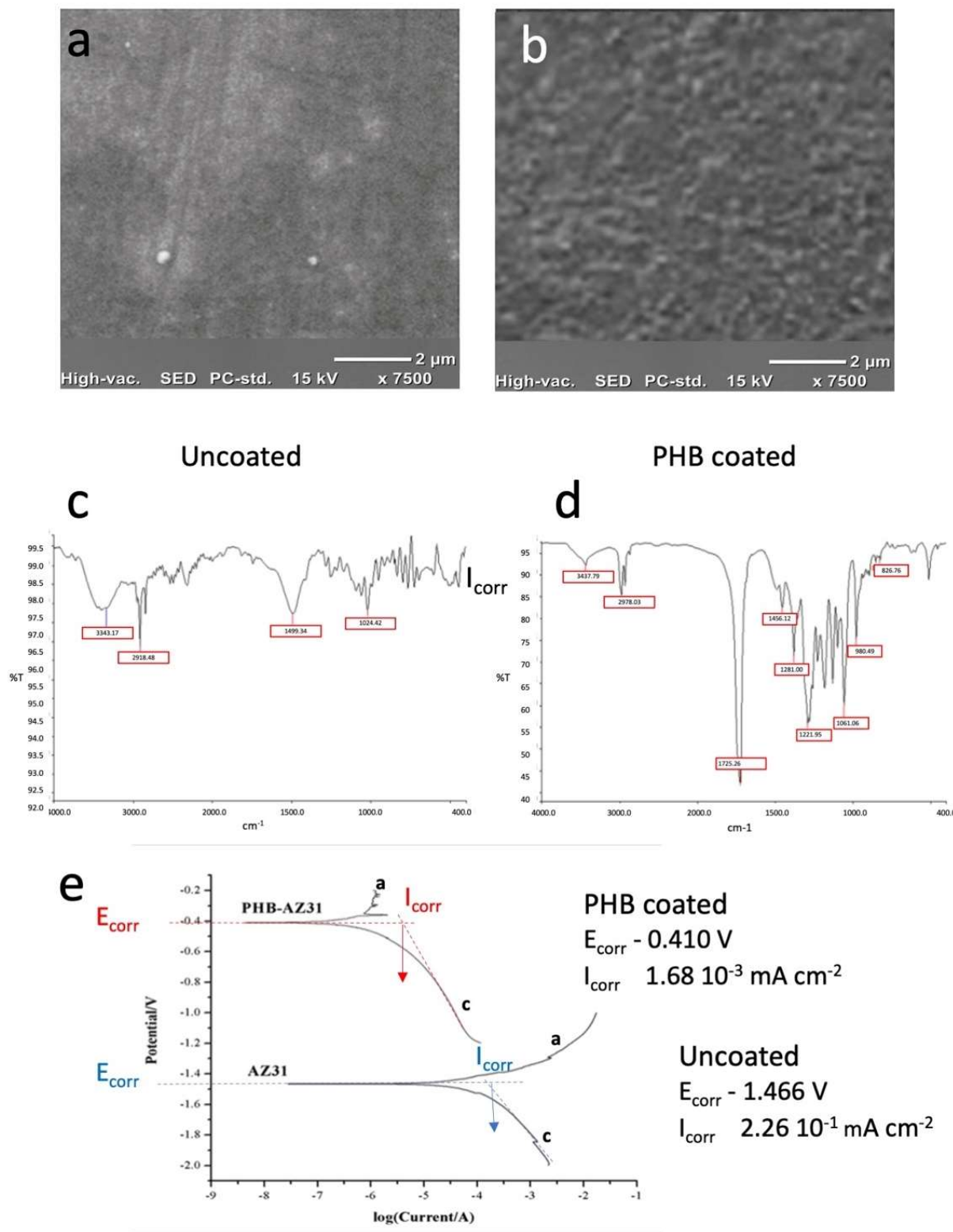

Figure 1. Characterization of the PHB coating. (a) Surface morphology of AZ31 (left) and (b) AZ31 coated PHB (right) under the scanning electron microscope (7500×). (c) FTIR spectra results of AZ31 (left), (d) and AZ31 PHB coating (right); (e) Comparison of polarization curves and natural corrosion potential (Ecorr) and current (Icorr) for PHB coated and uncoated AZ31 Mg alloy.

The surface of the thermally treated AZ31 Magnesium alloy exhibits a relatively smooth non continuous surface with snaking lines and partial bulge that were probably due to the spot formation of a non-homogeneous Magnesium hydroxide layer during the hydrothermal treatment. Conversely, PHB coated samples are characterized by much homogeneous surfaces (figure $1 b$ ).

It can be inferred that the polymer coating homogeneously covers and adheres to the Magnesium hydroxide layer.

The molecular characteristics and chemical composition of AZ31 and PHB coated AZ31 sample surfaces have been spectroscopically investigated. FTIR spectra are compared in Figure 1c and 1d. The left FTIR spectrum Figure 1c, relative to the uncoated alloy, shows the presence of an absorption band $3343 \mathrm{~cm}^{-1}$ which represents the existence of $(\mathrm{OH})$ bond possibly associated to a superficial layer of the Magnesium hydroxides. 
The surface absorption spectrum of the polymer coated samples, reported in Figure $1 \mathrm{~d}$, consistently with the standard spectrum of PHB, presents a $3437 \mathrm{~cm}^{-1}$ peak associated to the stretching vibration of hydroxyl $\mathrm{OH}$, the $2978 \mathrm{~cm}^{-1}$ peak of the stretching of saturated $\mathrm{CH}$, the $1725 \mathrm{~cm}^{-1}$ of the stretching of $\mathrm{C}=\mathrm{O}$, the $1456 \mathrm{~cm}^{-1}$ and $1381 \mathrm{~cm}^{-1}$ are $\mathrm{CH}_{3}$ and $-\mathrm{CH}_{2}$ - deformation vibration, the $1291 \mathrm{~cm}^{-1} \sim 1058 \mathrm{~cm}^{-1} \mathrm{PHB}$ ester band, and, finally, the $826 \mathrm{~cm}^{-1}$ absorption peak of $\mathrm{CH}_{2}$ groups.

These results confirm that AZ31 alloy sample has developed a Magnesium hydroxides surface layer [43] after hot water treatment that has been successively homogeneously covered by the thin film of PHB polymer.

Cathodic and anodic polarization plots are described in Figure 1e. The natural corrosion current ( $\left.\mathrm{I}_{\mathrm{corr}}\right)$ and natural corrosion potential ( $\left.\mathrm{E}_{\mathrm{corr}}\right)$ determined by Tafel extrapolation (dotted lines) for the PHB coated and uncoated Mg alloys are also reported on the Figure 1 e.

The Icorr value for the PHB coated sample is of two order of magnitude lower than that of the uncoated AZ31 alloy. Since Icorr is directly proportional to the corrosion rate [38], a drastic improvement in corrosion resistance is achieved by PHB coating and it can be attributed to the hindering of the oxidation and reduction reactions occurring at the metal interface.

Magnesium corrosion in aqueous media first implicates reaction of $\mathrm{H}_{2} \mathrm{O}$ with $\mathrm{Mg}$ to produce $\mathrm{Mg}(\mathrm{OH})_{2}$ and $\mathrm{H}_{2}$. The overall reaction comprises the anodic $\mathrm{Mg} \rightarrow \mathrm{Mg}^{2+}+2 \mathrm{e}^{-}$and the cathodic reaction $2 \mathrm{H}_{2} \mathrm{O}+2 \mathrm{e}^{-} \rightarrow \mathrm{H}_{2}+2 \mathrm{OH}$, which accounts for the increase of the solution $\mathrm{pH}$ [53-55]. After a hydrothermal passivation treatment (as is the case of our samples), the $\mathrm{Mg}$ AZ31 alloy surface was covered by a $\mathrm{Mg}(\mathrm{OH})_{2}$ layer. During the polarization tests, metal cation transport controls the anodic $\mathrm{Mg}$ dissolution kinetic at the metal interface beneath the $\mathrm{Mg}(\mathrm{OH})_{2}$ layer. The unstable in aqueous environment and porous layer cannot hinder electrolyte penetration and diffusive transport. Charge transfer associated with cathodic reactions can, then, freely occur both underneath and on top of this layer that can collapse increasing the charge transfer at advanced stages of the corrosion process.

The significantly higher than that measured for PHB coated samples natural corrosion current of the uncoated alloy depends on this high charged species mobility. For the PHB coated alloy, conversely, the exchange current density from the cathodic reaction is reduced because the more hydrophobic polymer film acts as a physical barrier that retards water penetration as well as electrons and ions transport.

Moreover, the abrupt deviation of the anodic branch (a) in the Tafel polarization plot of the PHB coated sample could be attributed to the passivation of the anode surface. The anodic metal passivation and dissolution rate reduction occur as the PHB coating significantly slows the diffusive mass transport of anions and cations [56].

Moreover, the formation of polar secondary $\mathrm{PHB}-\mathrm{Mg}^{2+}$ bonds (due to the high number of Oxygens present in the polymer structure) at the metal-polymer interface may further hinder anodic reactions [56]. The layer of PHB coating is also retarding in the bulk polymer anions diffusion from the SBF corroding medium to the metal interface resulting in a final natural corrosion current of about two orders of magnitude lower of that of the bare AZ31 sample.

The shift of natural corrosion potential of the PHB coated alloy towards the anodic direction and its passivation indicates that the polymer film acts as a physical barrier that strongly hinders the electrolytes anions migration from the SBF corroding solution to the cathode [56].

These anodic and cathodic polarization plots will be further discussed in next section in the relation to their correlations to wettability and the SBF corrosion tests in terms PHB diffusive barrier characteristics.

\subsection{Wettability, polarization curves and SBF corrosion tests}

Surface wettability of AZ31 Mg alloy was investigated by contact angle measurements. Water contact angles and reported in Table 2 for not hydrothermally treated, and hydrothermally treated with and without PHB coating. 
The wettability tests confirmed the presence of continuous surface layer of $\mathrm{Mg}(\mathrm{OH})_{2}$ on the hydrothermally treated samples

Table 2. Water contact angles for AZ Mg alloy not hydrothermally treated (first column), hydrothermally treated with the formation of a $\mathrm{Mg}(\mathrm{OH}) 2$ surface coating (second column), and hydrothermally treated with additionally PHB coating (third column).

\begin{tabular}{ccc}
\hline AZ31 Mg Alloy & AZ31 Mg Alloy + Mg(OH) & AZ31 Mg Alloy + Mg(OH $)_{2}+$ PHB \\
\hline $46.1^{\circ}$ & ${ }^{*} 42.2^{\circ}$ & ${ }^{*} 62,3^{\circ}$ \\
$\pm 2.5^{\circ}$ & $\pm 0.4^{\circ}$ & $\pm 0.3^{\circ}$ \\
\hline
\end{tabular}

*, significant difference $(\mathrm{p}<0.05),{ }^{* *}$, highly significant difference $(\mathrm{p}<0.01)$.

In particular, the contact angle of the not hydrothermally treated AZ31 alloy was about $46.1^{\circ}$, indicating a mild hydrophilic character. However, after the hydrothermal treatment, the measured contact angle was lowered to $42.2^{\circ}$ indicating that the hydrothermally formed Magnesium hydroxide increases sample surface hydrophilicity. Conversely, the presence of a PHB polymer coating on the hydrothermally treated AZ31 metal surface significantly increased the contact angle up to $62.3^{\circ}$ and then, considerably lowering its wettability compared to that of the only hydrothermally treated one. The more hydrophobic the outer layer, the lower the surface wettability and the lower the water penetration rate [53-55].

Surface wettability, then, could play a relevant role in the corrosion and biological responses of implanted devices because it influences water and solution electrolytes diffusion, the chemistry of corrosion, protein absorption and cell activity at the implant interface. This could be particularly significant in the case of Magnesium alloys prostheses. When implanted in the body, the Magnesium alloy will be in contact with the body fluids that will wet its surface starting a corrosion and resorption process that may become detrimental to its functionality if occurring at too high rates [57].

Our wettability test indicates that the presence of $\mathrm{Mg}(\mathrm{OH})_{2}$ layer increases the Magnesium alloy wettability and, then, any associated detrimental effects while the use of the PHB coating, which significantly reduces surface wettability and protects the metal surface, could allow to a better control of the erosion processes lengthening its functionality.

From the previous discussion it can be inferred that for implanted prostheses Magnesium erosion and ions release in the biological surrounding environment could directly related to electrochemical character of the reduction and oxidation reactions occurring at the metal interface and the external electrolytic solution.

Information on the corrosion rate, passivity, pitting susceptibility, as well as the cathodic and anodic behavior of an electrochemical system can be obtained by interpreting the polarization curves reported in figure $2 \mathrm{e}$ for bare and PHB coated Mg alloy.

The magnitude of natural corrosion current $I_{\text {corr }}$ and natural corrosion potential Ecorr act as driving forces dictating the type and rates of anodic and cathodic electrochemical processes that could take place at the metal/corroding solution interface.

It is generally agreed the larger is corrosion current density, the higher is corrosion rate, that is, the lower will be the corrosion resistance of the metal $[53,54]$.

The results of the 15 days SBF corrosion test on PHB coated and uncoated Mg AZ31 alloy carried out according to the ASTM-G31-72 are reported in Figure 2. Namely, pH change of the SBF corroding medium, mass of the $\mathrm{Mg}^{2+}$ corrosion ions released in the SBF, and gravimetric samples weight losses have been recorded each day before solution refreshing and are reported in figure $2 a, 2 b$ and $2 c$, respectively. The curves interpolating the experimental data reported in figure 2 have been obtained by mobile mean curve fitting with a period of 2 . 

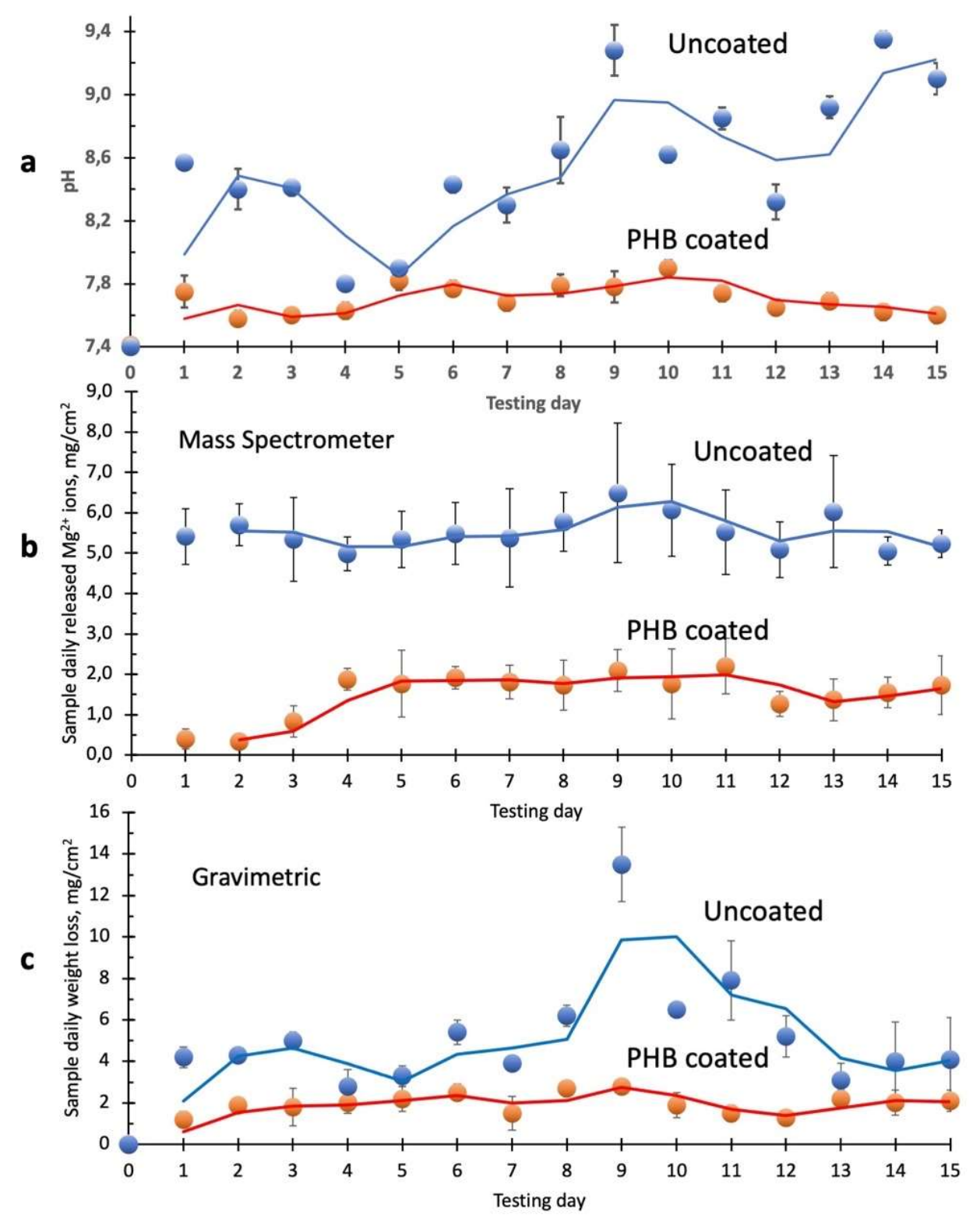

Figure 2. (a) $\mathrm{pH}$ of the $\mathrm{SBF}$ corroding medium, (b) mass of $\mathrm{Mg}^{2+}$ corrosion ions released in the SBF, and (c) gravimetric samples weight losses. Test were run according to ASTM-G31-72, SBF corroding medium was daily refreshed.

The PHB coated Mg AZ31 samples clearly exhibited in all three diagrams a significantly different corrosion behavior compared to that of the uncoated system.

At the end of each exposure day, the initial value of $\mathrm{pH}$ of the corroding medium raises from 7.4 to values steadily ranging from 7.6 to 7.8 over the entire 15 days test for the PHB coated metal samples (red curve in figure 2a), while that of the uncoated alloy (blue curve in figure 2a) presented a more scattered distribution and a higher basic character with $\mathrm{pH}$ values raised up to 8.0 - 9.5. For all the uncoated samples tested, an abrupt increase of $\mathrm{pH}$ after day $9^{\text {th }}-10^{\text {th }}$ of corrosion test was observed. This event could be attributed to the previously described porous $\mathrm{Mg}(\mathrm{OH})_{2}$ layer collapse due to the corrosion reactions and $\mathrm{Mg}^{2+}$ Ions ablation from the metal-hydroxide interface [52,53].

Magnesium, when exposed to aqueous environments, develops a superficial porous hydroxide film that only moderately protects the metal from external aggressive liquid environments since only partially hindering and slowing down any potential corrosion 
process [56,57]. However, $\mathrm{Mg}(\mathrm{OH})$, although only slightly soluble in water, undergoes severe modifications in presence of Chloride ions such it could occur in the case of use in contact with physiological solutions.

$\mathrm{Mg}(\mathrm{OH})^{2}$, reacting with $\mathrm{Cl}^{-}$, forms the highly soluble $\mathrm{MgCl}_{2}$ and molecular hydrogen [57]. This continuous dissolution process is accompanied by a progressive increase of the corroding medium basicity (as we have observed in our corrosion tests reported in figure 2a). In these conditions, pitting of Magnesium and embrittlement of $\mathrm{Mg}(\mathrm{OH})_{2}$ layer could occur at advanced stages of the corrosion process.

The abrupt $\mathrm{pH}$ rise at days $9^{\text {th }}-10^{\text {th }}$ can be then associated to the collapse of the Magnesium hydroxide layer which caused the direct exposure of the metal surface to the corroding medium. This occurrence, consistently with our experimental data and observed daily released $\mathrm{Mg}^{2+}$ ions (reported in figure $2 \mathrm{~b}$ as $\mathrm{mg}$ per sample $\mathrm{cm}^{2}$, and daily gravimetrically measured sample weight losses (reported in figure $2 \mathrm{c}$ as $\mathrm{mg}$ per sample $\mathrm{cm}^{2}$ ), parallely lead to an increase of $\mathrm{Mg}^{2+}$ ions concentration in the corroding medium and to a massive sample weight loss.

The mass of $\mathrm{Mg}^{2+}$ released from the uncoated Magnesium alloy, in fact, has been observed to be constantly higher than that of the PHB coated ones. This higher tendency to release $\mathrm{Mg}^{2+}$ ions is consistent with the previously described measurements of anodic and cathodic polarization curves and values of the natural corrosion current reported in figure 1e; the natural corrosion current Icorr of AZ31 coated PHB is, in fact, of two order of magnitude lower than that of the uncoated alloy, $1.6810^{-3} \mathrm{~mA} \mathrm{~cm}^{-2} \mathrm{vs} 2.2610^{-1} \mathrm{~mA} \mathrm{~cm}^{-2}$.

The electrochemical observations confirm the hypothesized corrosion mechanism of the SBF immersion corrosion tests where a higher diffusion resistance and lower cations and anions mobilities are induced by the PHB coating in AZ31 Mg alloy.

It can be supposed, then, that the degradation rate of the AZ31 coated PHB is significantly reduced by the presence of the polymeric coating film that acts as a membrane steadily controlling the diffusion flux of the ionic species (especially $\mathrm{Cl}^{-}$anions) from the SBF solution to the metal surface and the counter-diffusion of $\mathrm{Mg}^{2+}$ metal ions toward the external solution. Conversely, the mere presence of the less stable, especially in presence of Chloride ions, porous Magnesium hydroxide layer cannot equally guarantee a constant and effective corrosion control.

The hypothesized diffusive nature of the control exerted by the PHB membrane protecting the metal can be confirmed by the experimental data of Figure 3, where the cumulative amount of $\mathrm{Mg}^{2+}$ ions released in the daily refreshed SBF corroding solutions (data reported in Figure 2b) is plotted as a function of the test time for PHB coated and uncoated Mg AZ31 alloys.

A linear steady constant flux of $\mathrm{Mg}$ corrosion ions for the uncoated system (blue line in figure 3) can be observed since the early stages of the test while a time lag before reaching stationary flux is observed for the PHB coated system. A detail of the initial part of the $\mathrm{Mg}$ Ions release curve is reported in the left upper corner of Figure 3. The upward shape of the $\mathrm{Mg}$ Ions release curve before reaching steady constant slope is a characteristic observed in permeability tests and it is due to the initial diffusion and sorption of the solution components in the still unpenetrated polymer.

In presence of the PHB membrane, a diffusive control is exerted on electrolytes mobility before steady state conditions of ionic species flux can be reached. This diffusive resistance (time lag) in our tests can be can be evaluated from the intercept on the time scale( tlag, $_{\text {, }}$ ) of the linear part of the curve: namely, 1.9 days. Corrosion rates can be directly evaluated for PHB coated and uncoated alloys from the slopes of the curves at their stationary conditions. Corrosion rate for the PHB coated $\mathrm{Mg}$ alloy is almost four times slower than that of the uncoated system, namely, 1.25 and $5.5 \mathrm{mg} / \mathrm{cm}^{2} \mathrm{day}$, respectively (that according to ASTM-G31-72, correspond to metal corrosion rates of 7.2 and $31.6 \mu \mathrm{m} /$ day). 

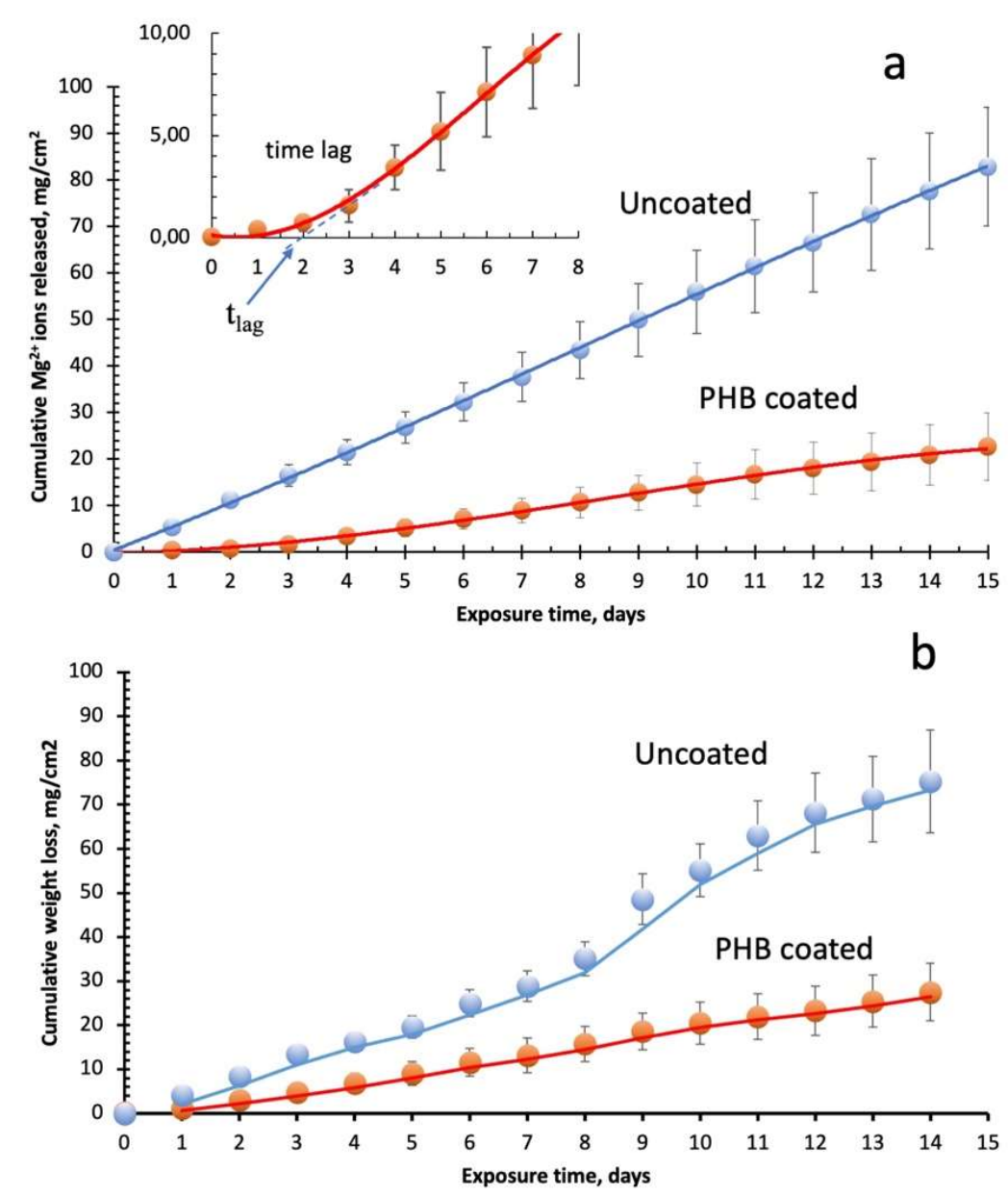

Figure 3. This is a figure. Schemes follow the same formatting.

Permeability test and time lag measurements in permeation tests have been proven $[58,59]$ to be effective methods to characterize permeability and diffusion coefficients of dissolved species. In the case of corrosion test, the driving force for diffusion is the difference in concentration of $\mathrm{Mg}^{2+}$ ions between the metal interface, where they are steadily generated by the corrosion reactions, and the corroding solution (which is maintained at a low $\mathrm{Mg}^{2+}$ concentration guarantee by the daily solution refreshments).

Due to the simple nature of the permeation experiment, such it can be schematized in our case, diffusive resistance can be directly obtained from experimental transient data preceding steady state permeation (time lag). The diffusion coefficient of $\mathrm{Mg}^{+2}$ ions in the PHB protective membrane can be evaluated using the standard time lag equation [58,59]:

$$
\mathrm{DMg}^{2+}=l^{2} / 6 \text { tlag }
$$

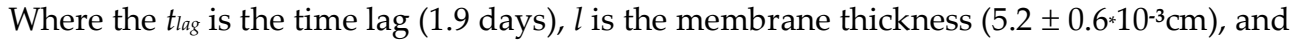
$\mathrm{DMg}^{2+}$ is the resulting diffusion coefficient, which in our testing condition is $2.7 \pm 0.5^{*} 10^{-11}$ $\mathrm{cm}^{2} / \mathrm{s}$. This $\mathrm{Mg}^{2+}$ ions diffusion coefficient, which accounts for the mutual cation and anion self-diffusion coefficients $D+$ and $D$ - and solubilities in the polymer, is coherent with the values observed for highly crystalline and hydrophobic polymers [60] such is PHB polymer. Due to the charge neutrality, the $\mathrm{Mg}^{2+}$ cations diffusion in the PHB bulk coating toward the external SBF solution is also depending of the counter diffusion of the anionic species (especially the $\mathrm{Cl}^{-}$ions that are directly involved in the metal corrosion process). 
As previously underlined analyzing the potentiometric polarization curves of the electrochemical characterization, the very low natural corrosion currents, and the shift of natural corrosion potential of the PHB coated alloy towards the anodic direction indicates that the polymer film is principally acting as a physical barrier that strongly hinders the electrolytes anions migration from the external SBF corroding solution to the metal.

\section{3. cytotoxicity (CCK-8 assay)}

Application of an indirect method provided experimental assessments for the biocompatibility assays. Potential detrimental effects on host cells of $\mathrm{Mg}$ alloys materials and treatments have been tested in vitro using an international standards ISO-10993-5 and ISO10993-12 that are commonly used to evaluate Magnesium alloys [45-52].

The SBF corrosion tests solutions (that we will name "extraction fluids") of the PHB coated and uncoated AZ31 alloy samples, which contain the corrosion by-products after one day exposure, were used to perform cytotoxicity trials at different dilutions, namely, $25 \%, 50 \%$ and $100 \%$ of the initial concentrated extracted medium.

The HUVECs viability in these two types of extraction fluids at different dilutions after 1 day, 3 days and 5 days, respectively, are summarized in Figure $4 a$, b, c.

After 1 day exposure, Figure $4 \mathrm{a}$, significant high differences in cell proliferations compared with the control are observed for 100\% AZ31 extraction fluid and its 50\% dilution, and for exposure to the $100 \%$ PHB-AZ31 extraction fluid. No significant differences with the control have been observed for the other groups.

After 3 days of culture, Figure $4 b$, significant differences for cell proliferation compared to the control are observed in 100\% AZ31 extract fluid, in its $25 \%$ dilution, and in the $25 \%$ dilution of the PHB-AZ31 extraction fluid.

Finally, after 5 days of culture, Figure 4c, only the 100\% AZ31 extraction fluid had a significant effect on cell proliferation while there was not significant difference between the other groups and the control.

These results showed that only in the early stage of culture a high Magnesium ion content in the corrosion extraction fluids has a positive effect on cell proliferation, while, at longer times, it is detrimental for cell proliferation.

The extraction fluid of the PHB coated Magnesium alloy, which is characterized by a significantly lower $\mathrm{Mg}$ Ions concentration (see Figure $2 \mathrm{~b}$ ) had a significant effect on cell proliferation only in the early stage of the culture (1 day).

\section{a}

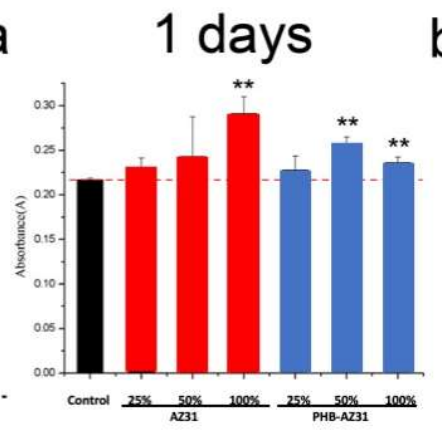

b

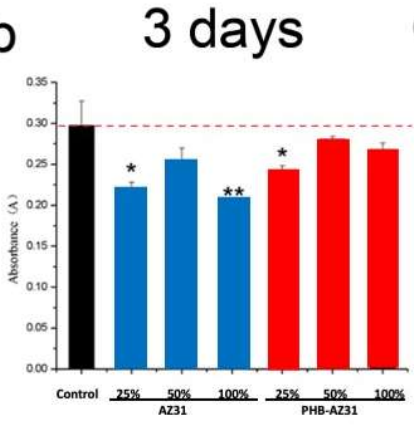

c 5 days

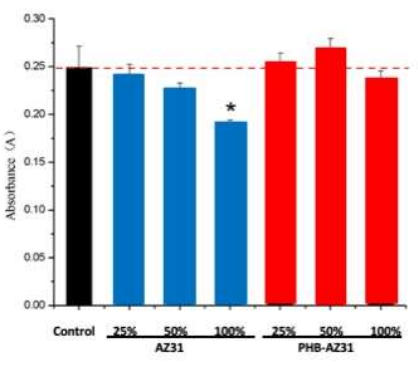

Figure 4. Proliferation of HUVECs cultured on extraction fluids after (a) 1, (b) 3 and (c) 5 days. ${ }^{*}$ significant difference $(\mathrm{p}<0.05),{ }^{* *}$, highly significant difference $(\mathrm{p}<0.01)$.

Table 4 resumes the details of the cytotoxicity tests for the AZ31 and PHB Coated AZ31 Extraction fluids and their dilutions. Levels of cytotoxicity were grade 0 for all extraction fluids and their dilutions when cultured for 1 day. After 3 days of culture, two of the three concentrations (25 and 100\%) of the AZ31 extraction fluid exhibited a cytotoxicity level of grade 2 while the $50 \%$ was 1 , all cytotoxicity levels for the PHB coated samples 
were of grade 1. After 5 days of cell culture, the cytotoxicity levels of from AZ31 samples fluids were all of grade 1 , while two concentrations ( 25 and $50 \%$ ) of the PHB coated samples fluid showed a cytotoxicity's of grade 0 and one of grade 1 .

It has been noticed that the PHB coated AZ31 Magnesium alloy extraction fluid has a less toxic behavior and the capacity to promote cells proliferation. This peculiar behavior derives from the lower concentration of corrosion $\mathrm{Mg}^{+2}$ ions that directly originates from the diffusion control exerted by the polymeric coating films on the fluxes of the dissolved ionic species (both from the metal surface to the solution and vice versa).

Table 3: Cytotoxicity (CCK-8 assay) test details.

\begin{tabular}{|c|c|c|c|c|c|c|c|c|c|c|}
\hline \multirow[b]{2}{*}{$\begin{array}{l}\text { Extraction } \\
\text { Fluid }\end{array}$} & \multirow[b]{2}{*}{$\begin{array}{l}\text { Conc. } \\
\%\end{array}$} & \multicolumn{3}{|c|}{ Cultured 1 Day } & \multicolumn{3}{|c|}{ Cultured 3 Days } & \multicolumn{3}{|c|}{ Cultured 5 Days } \\
\hline & & $O D$ & $\begin{array}{l}\text { RGR } \\
(\%)\end{array}$ & $\begin{array}{l}\text { Toxic } \\
\text { grade }\end{array}$ & $O D$ & $\begin{array}{l}\text { RGR } \\
(\%)\end{array}$ & $\begin{array}{l}\text { Toxic } \\
\text { grade }\end{array}$ & $O D$ & $\begin{array}{l}\text { RGR } \\
(\%)\end{array}$ & $\begin{array}{l}\text { Toxic } \\
\text { grade }\end{array}$ \\
\hline \multirow{3}{*}{ AZ31 } & 25 & $\begin{array}{c}0.229 \\
\pm 0.012 \\
\end{array}$ & 106 & 0 & $\begin{array}{c}0.220 \\
\pm 0.008\end{array}$ & 74 & 2 & $\begin{array}{c}0.242 \\
\pm 0.011\end{array}$ & 97 & 1 \\
\hline & 50 & $\begin{array}{c}0.243 \\
\pm 0.045\end{array}$ & 112 & 0 & $\begin{array}{c}0.255 \\
\pm 0.015 \\
\end{array}$ & 86 & 1 & $\begin{array}{c}0.227 \\
\pm 0.006 \\
\end{array}$ & 91 & 1 \\
\hline & 100 & $\begin{array}{c}0.291 \\
\pm 0.019\end{array}$ & 134 & 0 & $\begin{array}{c}0.198 \\
\pm 0.009\end{array}$ & 67 & 2 & $\begin{array}{c}0.192 \\
\pm 0.003\end{array}$ & 77 & 1 \\
\hline \multirow{3}{*}{$\begin{array}{c}\text { PHB } \\
\text { Coated } \\
\text { AZ31 }\end{array}$} & 25 & $\begin{array}{c}0.228 \\
\pm 0.016\end{array}$ & 105 & 0 & $\begin{array}{c}0.239 \\
\pm 0.009\end{array}$ & 80 & 1 & $\begin{array}{c}0.255 \\
\pm 0.010\end{array}$ & 102 & 0 \\
\hline & 50 & $\begin{array}{c}0.254 \\
\pm 0.011 \\
\end{array}$ & 109 & 0 & $\begin{array}{c}0.280 \\
\pm 0.004 \\
\end{array}$ & 94 & 1 & $\begin{array}{c}0.269 \\
\pm 0.010 \\
\end{array}$ & 108 & 0 \\
\hline & 100 & $\begin{array}{c}0.236 \\
\pm 0.016 \\
\end{array}$ & 109 & 0 & $\begin{array}{c}0.268 \\
\pm 0.008 \\
\end{array}$ & 90 & 1 & $\begin{array}{c}0.237 \\
\pm 0.008 \\
\end{array}$ & 95 & 1 \\
\hline
\end{tabular}

\subsection{Hemolysis}

According to the previous discussion the PHB polymer coating significantly reduces the MG AZ31 alloy corrosion rate in SBF and reduces the concentration of corrosion byproducts in the corroding medium.

Table 4 resumes the Optical Densities measurements utilized for the evaluation of the hemolysis ratio from the spectroscopic analysis of incubated extraction fluids of Magnesium alloy with and without PHB polymer coating with diluted blood and the positive and negative controls. In the last column is reported the $\mathrm{Mg}^{2+}$ concentration of the respective extraction fluids after $72 \mathrm{hrs}$ of PHB coated and bare Alloy sample conditioning.

The results indicate that the corrosion medium of the bare uncoated Magnesium alloy induces a serious hemolysis process with a rate that was as high as $37.61 \%$ compared to that of the PHB coated alloy samples where hemolysis rate was $4.19 \%$, showing better blood compatibility and meeting the requirements for application as medical materials (5\%).

The concentration of Magnesium ions has a great influence on blood as well as on tissue cells. An AZ31 Magnesium alloy implanted in the body, if characterized by a too high degradation rate, will lead to an excessive and dangerous increases of Magnesium ions concentration in the fluid surrounding the implant, with detrimental effect on the patient health.

After 72 hours SBF conditioning, the content of $\mathrm{Mg}^{+2}$ ions in the bare Magnesium alloy corrosion fluid was as high as $22.9 \pm 1.3 \mathrm{mmol} / \mathrm{L}$, while that of the PHB coated alloy was only $2.4 \pm 0.2 \mathrm{mmol} / \mathrm{L}$, which remains in the range of variability of the physiological fluids.

This result is in line with the hemolysis results discussed before. The too high $\mathrm{Mg}^{2+}$ ions concentration resulted in an inhibition of hemolysis that is to be attributed to the

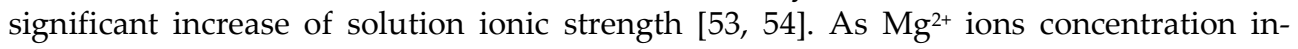
creases, the osmotic pressure of the solution will rise. The osmotic differentials can cause 
erythrocyte swelling and cell membrane rupture with release of free hemoglobin and consequent hemolysis of red blood cells.

Table 4. Detailed data of hemolysis rate testing.

\begin{tabular}{|c|c|c|c|}
\hline Sample & OD Value & Hemolysis rate & $\mathrm{Mg}^{2+}, \mathrm{mmol} / \mathrm{L}$ \\
\hline AZ31 Mg & $0.2487 \pm 0.0775$ & $37.61 \%$ & $22.9 \pm 1.3$ \\
\hline PHB coated AZ31 Mg & $0.0530 \pm 0.0117$ & $4.19 \%$ & $2.4 \pm 0.2$ \\
\hline Positive control & $0-6137 \pm 0.0117$ & & \\
\hline Negative control & $0.0285 \pm 0.0117$ & & \\
\hline
\end{tabular}

\subsection{NO assay}

Vascular endothelial cells are directly related to angiogenesis, and Nitric Oxide (NO) is one of the important regulatory signals of angiogenesis. In Figure 5 are reported the absorbance values of NO during. The results indicate that there is no difference between each group. We think the reason may be NO signal pathway is not closely related with the content of magnesium ions. Each group showed a better NO release compared with the normal group. This indicates that the Magnesium alloy material is appropriate for NO release.

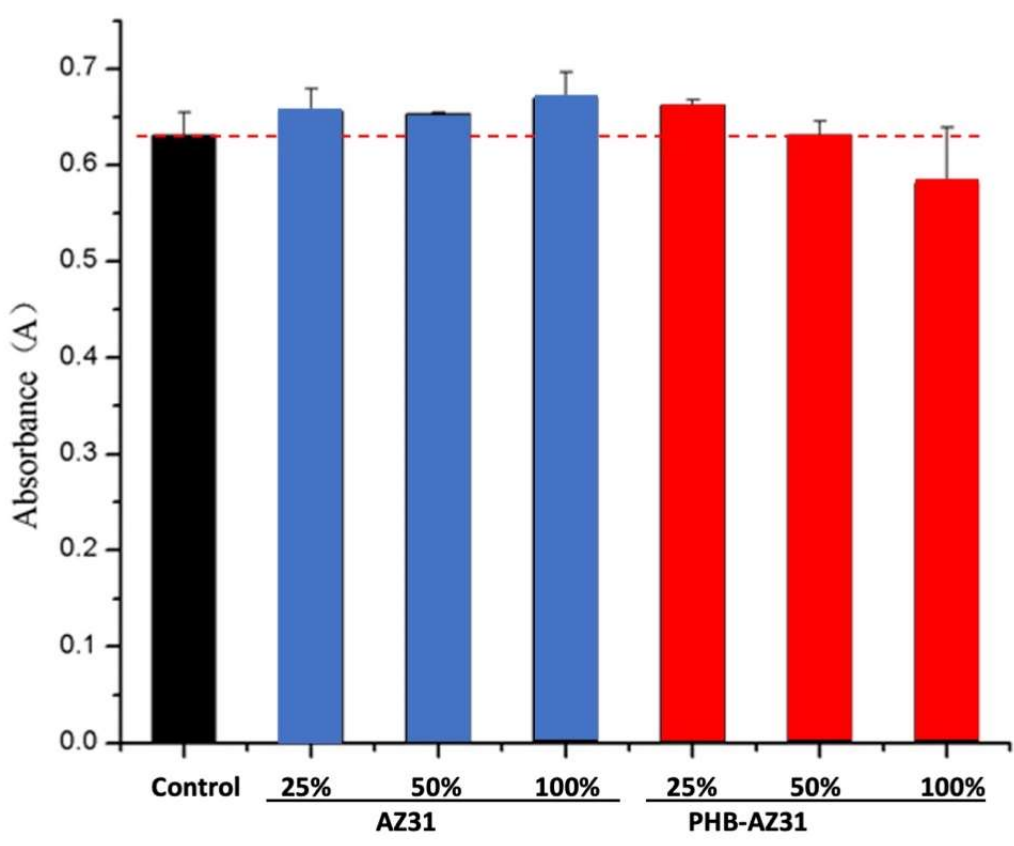

Figure 5. Nitric Oxides (NO) absorbance results of the different groups.

\subsection{T-AOC assay}

The normal physiological metabolism process of biological tissue can produce reactive oxygen species, and some environmental factors such as ultraviolet radiation, $\gamma$-ray irradiation, environmental pollution and other factors can also induce the production of reactive oxygen species. After producing the reactive oxygen species, it can lead to intracellular lipid, protein and DNA oxidative damage, therefore inducing oxidative stress, and then causing tumors, atherosclerosis, rheumatoid arthritis, diabetes, and liver damage etc. For these reasons, it is particularly necessary to detect the total antioxidant capacity of the cells.

Figure 6 shows the results of total antioxidant capacity. In general, the overall antioxidant capacity of the Magnesium alloy with PHB surface coating was significantly higher from that of the normal group, and the total antioxidant capacity was significantly 
improved, indicating that the Magnesium alloy material induce a very good enhancement on the total oxidation capacity of cells.

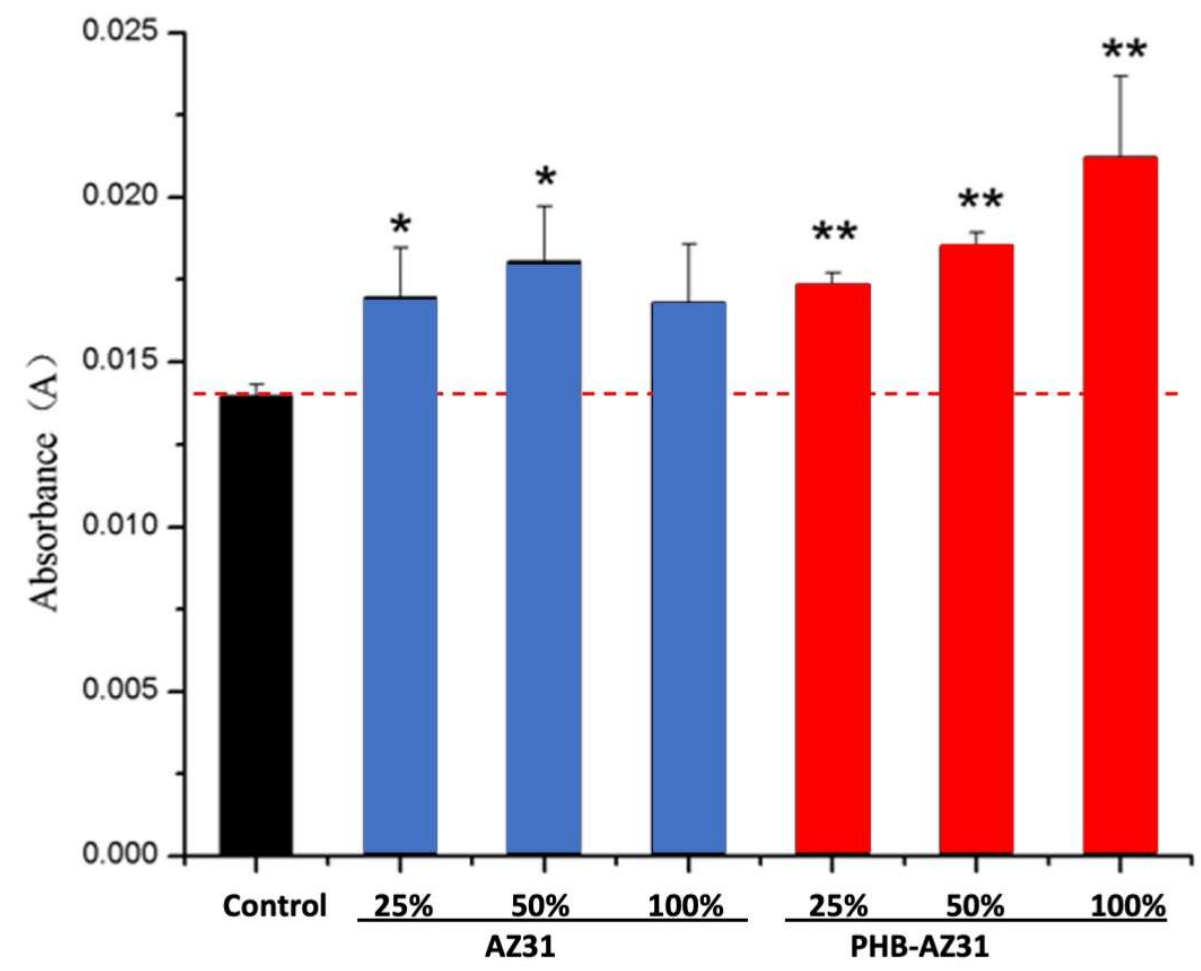

Figure 6. Total antioxidant capacity (T-AOC) contents of Different groups. $*$, significant difference $(\mathrm{p}<0.05),{ }^{* *}$, highly significant difference $(\mathrm{p}<0.01)$.

\section{Discussion}

The polymer coating was prepared by PHB dip-coating method while a Magnesium hydroxide film, as confirmed by FTIR spectra, was formed on the alloy metal surface by hydrothermal treatment. The hydroxyl of Magnesium hydroxide promotes the formation of hydrogen bonds with the PHB hydroxyls improving adhesion strength between polymer coating and Magnesium alloy surface. The corrosion natural current of uncoated Magnesium AZ31 alloy was two orders of magnitude higher than that of the PHB coated one demonstrating that the charges transport was drastically reduced by the presence of the polymeric coating.

It can be inferred that the reduced degradation rate of the AZ31 PHB coated system is to be associated to the presence of the polymeric coating film that acts as a membrane steadily controlling the diffusion flux of the ionic species (especially $\mathrm{Cl}$ - ions) from the SBF solution to the metal surface and the counter-diffusion of $\mathrm{Mg}^{++}$metal ions toward the external solution. The results of static corrosion experiments on PHB coated and uncoated AZ31 samples showed that under the same experimental conditions, the weight losses were drastically reduced by the presence of the polymer coating as well as the $\mathrm{Mg}$ ions concentration and $\mathrm{pH}$ of the corrosion SBF medium value were lower than that of the uncoated AZ31. The corrosion rate for the PHB coated Mg alloy was more stable and almost four times slower than that of the uncoated system, namely, 1.25 and $5.5 \mathrm{mg} / \mathrm{cm}^{2} \mathrm{day}$, respectively, that, according to ASTM-G31-72, correspond to surface ablation rates of 7.2 and $31.6 \mu \mathrm{m} /$ day, respectively.

These findings showed that the polymer coating could not only significantly enhance the corrosion resistance of Magnesium alloy materials but, due to the diffusive nature of the processes that driving the corrosion, it can be also used to program targeted resorption 
times. The control of the resorption rates after implantation of and, hence, of the $\mathrm{Mg}^{2+}$ ions concentration in the body fluids, could enlarge the field of application of these systems.

However, after implantation in the human body, a metal prosthesis biocompatibility must fulfill a complex chain process [48-50]. Firstly, blood and cell biocompatibility are two basic contents that must be evaluated. The hemolysis rate of PHB-AZ31 was lower than $5 \%$, meet the requirements of medical materials. Conversely, the hemolysis rate of bare AZ31 was $37.61 \%$, which might induce the more severe hemolytic phenomena because of the higher dissolution of Magnesium ions of the uncoated AZ31. When red blood cells contacted with materials, hemolysis phenomenon appeared because of the different osmotic pressures on both sides of the cell walls [51]. The hemolysis rate test proved that the coating of Magnesium alloy materials showed good blood compatibility. The cell compatibility tests were studied in the paper. The results showed that the corrosion extraction fluids with different concentrations infected the endothelial cells differently. The higher extract concentration of the uncoated AZ31 induced greater endothelial injuries. The PHBAZ31 extracts had no significant detrimental effect on cell proliferation due to of the protection and diffusive control exerted by the polymer coating film that maintains low and physiological levels of $\mathrm{Mg}^{2+}$ ions concentrations.

The cellular compatibility evaluation plays an important role in the evaluation of biological materials [52]. By CCK-8 kits testing cell proliferation, PHB as a protective layer promoted the cell proliferation. Angiogenesis means the formation of vascular lumen structure by end othelial cell proliferation and migration process based on the existing network of blood vessels. The vascular endothelial cells are directly related to angiogenesis. On the other hand, NO is one of the most important control signals of angiogenesis. Before and after coating, the NO content was not affected. Biological tissues can produce reactive oxygen species during the normal physiological process. In addition, some environmental factors such as ultraviolet radiation, gamma radiation and environmental pollution can induce to produce reactive oxygen species. When the reactive oxygen species is generated, it can lead to the oxidation damage of cell lipid, protein, and DNA. Once oxidative stress was induced, it in turn leads to the occurrence of a variety of tumors, atherosclerosis, rheumatoid, nervous system diseases, etc. Therefore, the T-AOC detection of cells is particularly necessary. However, compared with normal groups, the T-AOC of PBH-AZ31 had significant enhancement.

\section{Conclusion}

The major drawback of using the Magnesium and its alloys in many engineering applications is its low corrosion resistance, especially when exposed to aqueous electrolytic environments. However, this characteristic may become an intriguing property for biomedical applications, where the in vivo corrosion of the magnesium-based implant, if adequately controlled, involves the formation of a soluble, non-toxic oxide and $\mathrm{Mg}$ ions that is harmlessly and easily excreted in the urine. In addition, due to its functional roles and presence in bone tissue, Magnesium may have stimulatory effects on the growth of new bone tissue [27-30]

Thus, it is predictable that magnesium and its alloys could be applied as lightweight, degradable, load bearing orthopedic implants, which would remain present in the body and maintain mechanical integrity over a planned controlled time scale while the bone tissue heals, eventually being replaced by natural tissue [31,32] . The unfortunate complication is that pure magnesium can corrode too quickly in the physiological $\mathrm{pH}(7.4-7.6)$ and high chloride environment of the physiological system

Polymer PHB was then investigated in our study as a potential Magnesium alloy corrosion-controlling coating. The SEM analysis showed that the morphology of AZ31 magnesium alloy was changed, depicting smooth and flat features formed after PHB coating treatment. The FTIR spectra confirmed the molecular and chemical composition for AZ31 and AZ31 coated PHB. It indicated that AZ31 had indeed formed a Magnesium hydroxides layer on exposed surface after hot water treatment. Wettability studies confirmed that PHB coating made the surfaces less hydrophilic. Static degradation and the 
electrochemical experiments demonstrated that the corrosion rate decreased for PHB coated AZ31 as compared to the untreated surfaces. The corrosion controlling ability can be related to the diffusive resistance to corroding molecules diffusion to the metal surface and $\mathrm{Mg}$ Ions counter diffusion to the solution exerted by the polymeric film. Degradation rate can be then further reduced by increasing the polymeric film thickness and, hence, the diffusive hindering. This feature can allow to specifically tailor the coating thicknesses for different specific resorbable prosthetic applications.

The in vitro analysis by indirect MTS assay showed the experimental group may promote the proliferation of cells due to the presence and control of the PHB polymer coating. The hemolysis rate of the material indicated PHB coating was indeed effective to slow down the degradation rate of Magnesium alloy. Ultimately, the NO and T-AOC analysis displayed PHB coating showed good biocompatibility.

This demonstrates that the PHB polymer coating can effectively avoid, in a potential clinical application of this $\mathrm{Mg}$ alloy, the detrimental effect of an intense and uncontrolled release in the body of $\mathrm{Mg}$ ions by reducing the metal degradation rate (that has been evaluated from the corrosion tests reported in Figure $3 a$ to be 4 times slower than that of the bare uncoated Mg alloy, namely, $1.25 \mathrm{vs} 5.5 \mathrm{mg} / \mathrm{cm}^{2}$ day) and, hence, reducing the concentration of Magnesium ions around this potential resorbable implant. Moreover, due to the diffusive nature of the control exerted by the polymer coating, corrosion rate may be programmed to specific times and level of $\mathrm{Mg}$ ions concentrations by properly modifying the coating thickness.

\begin{abstract}
Author Contributions: For research articles with several authors, a short paragraph specifying their individual contributions must be provided. The following statements should be used "Conceptualization, G.W. and A.A.; methodology, L.W., R.A. and V.P..; validation, Z.H.., J.T. and S.G.; formal analysis, A.A.. Y.C.; investigation, X.X.; resources, X.X.; data curation, X.X.; writing - original draft preparation, G.W. and A.A.; writing - review and editing, A.A..; visualization, R.A., A.A.; supervision, G.W. and A.A.; funding acquisition, G.W. All authors have read and agreed to the published version of the manuscript.

Funding: Acknowledgement: This study was partially supported by grants from the National Key Technology R \& D Program of China (2016YFC1102305), the National Natural Science Foundation of China (11332003, 31700826, 31700826), the Visiting Scholar Foundation of Key Laboratory of Biorheological Science and Technology (Chongqing University), Ministry of Education (CQKLBST2016-001), Chongqing Research Program of Basic Research and Frontier Technology (cstc2017jcyjAX0284) as well as the Public Experiment Center of State Bioindustrial Base (Chongqing), China.
\end{abstract}

Institutional Review Board Statement: Not applicable.

\title{
References
}

1. Hou, Zhengjun; Yan, Wenhua; Li, Tianhan; Wu, Wei; Cui, Yuliang; Zhang, Xiaojuan; Chen, You-Peng; Yin, Tieying; Qiu, Juhui; Wang, Guixue, Lactic acid-mediated endothelial to mesenchymal transition through TGF- $\beta 1$ contributes to in-stent stenosis in poly-L-lactic acid stent. International Journal of Biological Macromolecules. 2020, 155, 1589-1598.

2. Song Lin; Xiaolin Ran; Xinhao Yan; Wenhua Yan; Qilong Wang; Tieying Yin; Jack G Zhou; Tingzhang Hu; Guixue Wang, Corrosion behavior and biocompatibility evaluation of a novel zinc-based alloy stent in rabbit carotid artery model. J Biomed Mater Res B, 2019, 107, 1814-1823.

3. Fan G A, Yh B, Gl C, et al. Layer-by-layer deposition of bioactive layers on magnesium alloy stent materials to improve corrosion resistance and biocompatibility-ScienceDirect. Bioactive Materials, 2020, 5, 611-623.

4. Ostrowski N J, Lee B, Roy A, et al. (2013) Biodegradable poly(lactide-co-glycolide) coatings on magnesium alloys for orthopedic applications. Journal of materials science 24: 85-96.

5. Mark P, Staiger, et al. (2006) Magnesium and its alloys as orthopedic biomaterials: A review. Biomaterials.

6. Kotaro H, Kunio M, Xinsheng H, et al. (2013) Fabrication of Mg alloy tubes for biodegradable stent application. Materials science \& engineering c materials for biological applications 33: 4746-4750.

7. M. Salahshoor, Y. Guo. (2012) Biodegradable orthopedic magnesium-calcium (MgCa) alloys, processing, and corrosionperformance. Materials (Basel) 5: 135-155.

8. Witte F, Ulrich H, Rudert M, et al. (2007) Biodegradable magnesium scaffolds: Part 1: Appropriate inflammatory response. Journal of biomedical materials research part a 81: 748-756.

9. Witte F, Ulrich H, Rudert M, et al. (2007) Biodegradable magnesium scaffolds: Part 1: Appropriate inflammatory response. Journal of biomedical materials research part a 81: 757-765. 
10. Windhagen, Radtke, H.,K. Weizbauer A., et al. (2013) Biodegradable magnesium-based screw clinically equivalent to titanium screw in hallux valgus surgery: short term results of the first prospective, randomized, controlled clinical pilot study. Biomed Eng 12: 62.

11. Wu G, Ibrahim J M, Chu P K. (2013) Surface design of biodegradable magnesium alloys-A review. Surface and Coatings Technology 233: 2-12.

12. S. Chen, S. Guan, W. Li, et al. (2011) In vivo degradation and bone response of a composite coating on Mg-Zn-Ca alloy prepared by microarc oxidation and electrochemical deposition. J Biomed Mater Res B Appl Biomater 533-543.

13. Sezer N, Evis Z, Ko M. Additive manufacturing of biodegradable magnesium implants and scaffolds: Review of the recent advances and research trends. Journal of Magnesium and Alloys, 2020.

14. 14 Aversa, R., Petrescu, V., Apicella, A., \& Petrescu, I. T. (2016). The basic elements of life's. American Journal of Engineering and Applied Sciences, 9(4), 1189-1197. doi:10.3844/ajeassp.2016.1189.1197

15. 15 Aversa, R., Tamburrino, F., Petrescu, R. V. V., Petrescu, F. I. T., Artur, M., Chen, G., \& Apicella, A. (2016). Biomechanically inspired shape memory effect machines driven by muscle like acting NiTi alloys. American Journal of Applied Sciences, 13(11), 1264-1271. doi:10.3844/ajassp.2016.1264.1271

16. Jacobs J J, Hallab N J, Skipor A K, et al. (2004) Metal Degradation Products: A Cause for Concern in Metal-Metal Bearings? Clinical Orthopaedics \& Related Research 417: 139-147.

17. Granchi D, Ciapetti G, Stea S, et al. (1999) Cytokine release in mononuclear cells of patients with Co-Cr hip prosthesis. Biomaterials 20: 1079.

18. Niki Y, Matsumoto H, Suda Y, et al. (2003) Metal ions induce bone-resorbing cytokine production through the redox pathway in synoviocytes and bone marrow macrophages. Biomaterials 24: 1447-1457.

19. Waizy H, Seitz J M, Reifenrath J, et al. (2013) Biodegradable magnesium implants for orthopedic applications. Journal of Materials Science 48: 39-50.

20. Xu R, Yang X, Kai W S, et al. (2012) Improved corrosion resistance on biodegradable magnesium by zinc and aluminum ion implantation. Applied Surface Science 263: 608-612.

21. Xin Y, Liu C, Zhang X, et al. (2007) Corrosion behavior of biomedical AZ91 magnesium alloy in simulated body fluids. Journal of Materials Research 22: p.2004-2011.

22. 20. Jacobs J.J.M.D., Hallab N.J.P., Skipor A.K.M.S., Urban R.M.A.S. Metal Degradation Products: A Cause for Concern in MetalMetal Bearings? Clin. Orthop. Relat. Res. 2003;417:139-147.

23. Witte F, Fischer J, Nellesen J, et al. (2006) In vitro and in vivo corrosion measurements of magnesium alloys. Biomaterials 27: 1013-1018.

24. Li L, Gao J, Wang Y. (2004) Evaluation of cyto-toxicity and corrosion behavior of alkali-heat-treated magnesium in simulated body fluid. Surface \& Coatings Technology 185: 92-98.

25. Liu C, Xin Y, Tian X, et al. (2007) Corrosion behavior of AZ91 magnesium alloy treated by plasma immersion ion implantation and deposition in artificial physiological fluids. Thin Solid Films 516: p.422-427.

26. Wang J, Tang J, Zhang P, et al. (2012) Surface modification of magnesium alloys developed for bioabsorbable orthopedic implants: A general review. Journal of Biomedical Materials Research Part B Applied Biomaterials 100B: 0-0.

27. Liu C, Xin Y, Tian X, Chu PK. (2007) Corrosion behavior of AZ91 magnesium alloy treated by plasma immersion ion implantation and deposition in artificial physiological fluids. Thin Solid Films 516: 422-7.

28. Wang X, Zeng X, Wu G, Yao S, Lai Y. (2007) Effects of tantalum ion implantation on the corrosion behavior of AZ31 magnesium alloys. J Alloy Compd 437: 87-92.

29. Zhou H, Chen F, Yang Y, Wan H, Cai S. (2008) Study on process of ion implantation on AZ31 magnesium alloy. Key Eng Mater 373: 342-5.

30. Orlowski M, Rübben A. (2008) Bioresorbable metal stents with controlled resorption. World Intellectual property organization patent WO 092436A2:p.1-26.

31. Bertsch T, Borck A. (2008) Biocorrodible metallic implant having a coating or cavity filling made of gelatin. US patent 0058923A1: p.1-3.

32. Zharkova II, Staroverova OV, Voinova VV, Andreeva NV, Shushckevich AM, Sklyanchuk ED, Kuzmicheva GM, Bespalova AE, Akulina EA, Shaitan KV, Okhlov AA. Biocompatibility of electrospun poly(3-hydroxybutyrate) and its composites scaffolds for tissue engineering. Biomed Khim. 2014 Sep-Oct; 60(5):553-60. Russian. doi: 10.18097/pbmc20146005553. PMID: 25386884.

33. Adden N. (2009) Implant of a biocorrodable magnesium alloy and having a coating ofa biocorrodable polyphosphazene. US patent 0048660A1: p.1-3.

34. Zhang XP, Zhao ZP, Wu FM, Wang YL, Wu J. (2007) Corrosion and wear resistance of AZ91D magnesium alloy with and without micro-arc oxidation coating in Hank's solution. J Mater Sci 42: 8523-8.

35. Xu X, Lu P, Guo M, Fang M. (2010) Cross-linked gelatin/nanoparticles composite coating on micro-arc oxidation film for corrosion and drug release. Appl Surf Sci 256: 2367-71.

36. Jo J H, Hong J Y, Shin K S, et al. (2012) Enhancing biocompatibility and corrosion resistance of Mg implants via surface treatments. Journal of Biomaterials Applications 27:469-476.

37. Salunke P, Shanov V, Witte F. (2011) High purity biodegradable magnesium coating for implant application. Materials Science \& Engineering B 176: 1711-1717.

38. Wong H M, Yeung K W, Lam K O, et al. (2010) A biodegradable polymer-based coating to control the performance of magnesium alloy orthopaedic implants. Biomaterials 31: 2084-2096. 
39. Aversa, R., Petrescu, R. V., Petrescu, F. I. T., Perrotta, V., Apicella, D., Apicella, A. (2021). Biomechanically tunable nano-silica/phema structural hydrogels for bone scaffolding. Bioengineering, 8(4) doi:10.3390/bioengineering8040045

40. Witte F, Hort N, Vogt C, et al. (2008) Degradable biomaterials based on magnesium corrosion. Current Opinion in Solid State \& Materials Science 12: 63-72.

41. Gray-Munro J E, Seguin C, Strong M. (2009) Influence of surface modification on the in vitro corrosion rate of magnesium alloy AZ31. Journal of Biomedical Materials Research Part A 91: 221.

42. Staiger M P, Pietak A M, Huadmai J, et al. (2006) Magnesium and its alloys as orthopedic biomaterials: a review. Biomaterials 27: 1728.

43. Gogolewski S, Jovanovic M, Perren S M, et al. (1993) Tissue response and in vivo degradation of selected polyhydroxyacids: Polylactides (PLA), poly(3-hydroxybutyrate) (PHB), and poly (3-hydroxybutyrate-co-3-hydroxyvalerate) (PHB/VA). Journal of Biomedical Materials Research 27: 1135.

44. Kostopoulos L, Karring T. (1994) Augmentation of the rat mandible using guided tissue regeneration. Clinical Oral Implants Research 5: 75-82.

45. Shishatskaya, Ekaterina \& Volova, T \& Gordeev, SA \& Puzyr, AP. (2005). Degradation of P(3HB) and P(3HB-co-3HV) in biological media. Journal of biomaterials science. Polymer edition. 16. 643-57. 10.1163/1568562053783678.

46. Li T, Qi K. (1994) Microbial Polyesters: The Polymer of the Future, Exploration of Nature. 13: 35-41.

47. Baptist J N. (1999) Process for Preparing Poly $\beta$-Hyroxybutyric Acid: US, 3044942[P].

48. Wang Z, Yan J, Zheng Q, et al. (2012) CyclinD1, CDK4, and P21 expression by IEC-6 cells in response to NiTi alloy and polymeric biomaterials. Materials Science \& Engineering C 32: 2183-2189.

49. Rahmany M B, Van D M. (2013) Biomimetic approaches to modulate cellular adhesion in biomaterials: A review. Acta Biomaterialia 9: 5431.

50. Hornberger H, Virtanen S, Boccaccini A R. (2012) Biomedical coatings on magnesium alloys-A review. Acta Biomaterialia 8:2442-2455.

51. Mueller P P, May T, Perz A, et al. (2006) Control of smooth muscle cell proliferation by ferrous iron. Biomaterials 27: 2193-2200.

52. Walter R, Kannan M B. (2011) In-vitro degradation behaviour of WE54 magnesium alloy in simulated body fluid. Materials Letters 65: 748-750.

53. Song J, Van Ooij WJ. Bonding and corrosion protection mechanisms of gamma-APS and BTSE silane films on aluminum substrates. Journal of Adhesion Science and Technology. 2003;17:2191-221.

54. Jones D. A., Amy P. S. , A Thermodynamic Interpretation of Microbiologically Influenced Corrosion, 2002, Corrosion 58 (8): 638-645., https://doi.org/10.5006/1.3287692

55. Song G, Atrens A. Understanding Magnesium Corrosion-A Framework for Improved Alloy Performance. Advanced Engineering Materials. 2003;5:837-58.

56. Zhu D, van Ooij WJ. Corrosion protection of AA 2024-T3 by bis-[3-(triethoxysilyl)propyl]tetrasulfide in sodium chloride solution.: Part 2: mechanism for corrosion protection. Corrosion Science. 2003;45:2177-97

57. Liu X, Yue Z, Romeo T, Weber J, Scheuermann T, Moulton S, Wallace G. Biofunctionalized anti-corrosive silane coatings for magnesium alloys. Acta Biomater. 2013 Nov;9(10):8671-7. doi: 10.1016/j.actbio.2012.12.025. Epub 2013 Jan 11. PMID: 23313945.

58. Jyoti, G.; Keshav, A.; Anandkumar, J. Review on Pervaporation: Theory, Membrane Performance, and Application to Intensification of Esterification Reaction. J. Eng. 2015, 2015, 1-24.

59. Ball, I.J.; Huang, S.; Wolf, R.A.; Shimano, J.Y.; Kaner, R.B. Pervaporation studies with polyaniline membranes and blends. J. Membr. Sci. 2000, 174, 161-176

60. Hideyuki Sawada, Yoichi Takahashi, Sou Miyata, Shinji Kanehashi, Shuichi Sato, Kazukiyo Nagai, Gas Transport Properties and Crystalline Structures of Poly(lactic acid) Membranes, Transactions of the Materials Research Society of Japan, 2010, Volume 35, Issue 2, Pages 241-246, Released April 18, 2014, Online ISSN 2188-1650, Print ISSN 13823469, https://doi.org/10.14723/tmrsj.35.241, 